EPJ Web of Conferences 59, 13017 (2013)

DOI: $10.1051 /$ epjconf/20135913017

(C) Owned by the authors, published by EDP Sciences, 2013

\title{
Summary of the first neutron image data collected at the National Ignition Facility
}

Gary P. Grim ${ }^{1, a}$, Thomas N. Archuleta ${ }^{1}$, Robert J. Aragonez ${ }^{1}$, Dennis P. Atkinson ${ }^{2}$, Steven H. Batha ${ }^{1}$, Maria A. Barrios ${ }^{2}$, Dan E. Bower ${ }^{2}$, David K. Bradley ${ }^{2}$, Robert A. Buckles ${ }^{3}$, David D. Clark ${ }^{1}$, Deborah J. Clark ${ }^{1}$, Jerry R. Cradick ${ }^{3}$, Chris Danly ${ }^{1}$, Owen B. Drury ${ }^{2}$, Valerie E. Fatherley ${ }^{1}$, Joshua P. Finch ${ }^{5}$, Felix P. Garcia ${ }^{1}$, Robert A. Gallegos ${ }^{1}$, Nevzat Guler ${ }^{1}$, Steven M. Glenn ${ }^{2}$, Albert H. Hsu ${ }^{1}$, Nobuhiko Izumi, Steven A. Jaramillo ${ }^{1}$, George A. Kyrala ${ }^{1}$, Sebastien Le Pape ${ }^{2}$, Eric N. Loomis ${ }^{1}$, Danielle Mares ${ }^{1}$, Drew D. Martinson ${ }^{1}$, Tammy $\mathrm{Ma}^{2}$, Andrew J. Mackinnon, Frank E. Merrill ${ }^{1}$, George L. Morgan ${ }^{1}$, Carter Munson ${ }^{1}$ Thomas J. Murphy ${ }^{1}$, Paul J. Polk ${ }^{1}$, Derek W. Schmidt ${ }^{1}$, Riccardo Tommasini ${ }^{2}$, Ian L. Tregillis ${ }^{1}$, Adelaida C. Valdez ${ }^{1}$, Petr L. Volegov ${ }^{1}$, Tai-Sen F. Wang ${ }^{1}$, Carl H. Wilde ${ }^{1}$, Mark D. Wilke ${ }^{1}$, Douglas C. Wilson ${ }^{1}$, John M. Dzenitis ${ }^{2}$, Brian Felker², David N. Fittinghoff', Matthias Frank ${ }^{2}$, Sean N. Liddick², Michael J. Moran², George P. Roberson², Paul Weiss ${ }^{2}$, Morris I. Kauffman ${ }^{4}$, Steve S. Lutz ${ }^{3}$, Robert M. Malone ${ }^{4}$ and Albert Traille ${ }^{3}$

1 Los Alamos National Laboratory, Los Alamos, NM 87545, USA

2 Lawrence Livermore National Laboratory, Livermore, CA 94550, USA

${ }^{3}$ National Security Technologies, Livermore Operations, Livermore CA 94550, USA

${ }^{4}$ National Security Technologies, Los Alamos Operations, Los Alamos, NM 87544, USA

${ }^{5}$ National Security Technologies, Special Technology Laboratory, Santa Barbara, CA 93111, USA

${ }^{6}$ Global Nuclear Fuel, Wilmington, North Carolina 28402, USA

\begin{abstract}
A summary of data and results from the first neutron images produced by the National Ignition Facility (NIF), Lawrence Livermore National Laboratory, Livermore, CA, USA are presented. An overview of the neutron imaging technique is presented, as well as a synopsis of data and measurements made to date. Data from directly driven, DT filled microballoons, as well as indirectly driven, cryogenically layered ignition experiments are presented. The data show that the primary cores from directly driven implosions are approximately twice as large, $64 \pm 3 \mu \mathrm{m}$, as indirectly driven cores, $25 \pm 4$ and $29 \pm 4 \mu \mathrm{m}$ and more asymmetric, $\mathrm{P} 2 / \mathrm{P} 0=47 \%$ vs. $-14 \%$ and $7 \%$. Further, comparison with the size and shape of X-ray image data on the same implosions show good agreement, indicating X-ray emission is dominated by the hot regions of the implosion.
\end{abstract}

\footnotetext{
ae-mail: gpgrim@lanl.gov
}

This is an Open Access article distributed under the terms of the Creative Commons Attribution License 2.0, which permits unrestricted use, distribution, and reproduction in any medium, provided the original work is properly cited. 


\section{EPJ Web of Conferences}

\section{INTRODUCTION}

The National Ignition Facility has begun the quest to systematically determine the conditions necessary to ablatively drive a cryogenically layered DT filled capsule to the pressures and temperatures necessary to induce thermonuclear burn, with the goal of obtaining energetic break-even. To achieve the requisite drive conditions, it is necessary to carry out a series of "tuning" experiments where the empirical relationship between key fuel assembly properties, such as size and shape, can be correlated with the laser drive parameters, such as pointing within the hohlraum, power, power balance, pulse timing, etc. Images of where fusion neutrons are produced and scattered within the highly compressed fuel assembly provide key information on the efficiency of the implosion. This information, when combined with other data, such as ion temperature, yield, bang-time, etc, can be used to provide a detailed picture of the burning plasma and the material surrounding it, allowing measurements of fuel volume, areal density, pressure, adiabat, etc. In this work, the first neutron image data produced by the NIF neutron imaging diagnostic is presented. In section 2 a brief synopsis of the method is provided, followed by a summary of the data collected to date in section 3, including a comparison with X-ray image data. Section 4 summarizes the results.

\section{THE NIF NEUTRON IMAGER}

Fig. 1 illustrates how neutron imaging works and what information it can provide. As the core of the fuel in DT implosions reaches temperatures and densities where a large number of DT fusions occur, a corresponding flux of $14.1 \mathrm{MeV}$ neutrons will be produced and stream from the hot-spot. As these neutrons leave the capsule, they will pass through colder, denser fuel that is not participating in the burn. A significant fraction of these neutrons will scatter. These scatters result in a spectrum of neutron kinetic energies that extends from $14.1 \mathrm{MeV}$, down to thermal energies. The fraction of neutrons found in the energy band from 10 to $12 \mathrm{MeV}$ is directly related to the areal density of the cold dense fuel, and probes the size and shape of the dense mass surrounding the hot spot.

Neutron imaging of inertial confinement fusion implosions is a well established diagnostic technique [1-5]. The diagnostic principle is based on aperture imaging methods regularly used in optics. In inertial confinement fusion experiments, source sizes are typically $100 \mu \mathrm{m}$ in diameter. The data collected by the NIF neutron imaging diagnostic are collected in the equatorial plane of the NIF coordinate system, using a $20 \mathrm{~cm}$ long gold and tungsten aperture body located $32.5 \mathrm{~cm}$ from the target. Neutrons are detected in a $170 \mathrm{~mm} \times 170 \mathrm{~mm} \times 5 \mathrm{~cm}$ volume of coherently arrayed, $250 \mu \mathrm{m}$ diameter, BCF99-55 scintillating fibers positioned $2800 \mathrm{~cm}$ from the target. Light from this volume is collected in two digital recording systems, electro-optically gated on neutron flight times corresponding to energy gates of $10-12 \mathrm{MeV}$ and 13-17 MeV. The details of the diagnostic development are published in a number of papers [6-8] and the details of this system are described in a separate submission by Fittinghoff et al. [9].

\section{NEUTRON IMAGING DATA}

\subsection{Direct drive implosions}

The first image data were collected on 18 Feb. 2011, shot N110217. Images were collected of neutrons produced in a directly driven, $1.5 \mathrm{~mm}$ diameter, $4 \mu \mathrm{m}$ thick glass capsule filled with $10 \mathrm{~atm}$. of equimolar DT. The raw image data was corrected for detector and background systematics and cropped around the center of each projected pinhole location. The cropped images were then reconstructed using an Expectation Maximization Maximum Likelihood algorithm [11]. The results of this reconstruction are shown in Fig. 1a. The shape of the core, as described by coefficients of a Legendre polynomial fit of the radius versus angle at the $17 \%$ of peak signal contour are: $\mathrm{P} 0=64 \pm 3 \mu \mathrm{m}$ and $\mathrm{P} 2 / \mathrm{P} 0=47 \pm 4 \%$. The significant asymmetry of the implosion is due to the difficulty in the polar distribution of the laser 


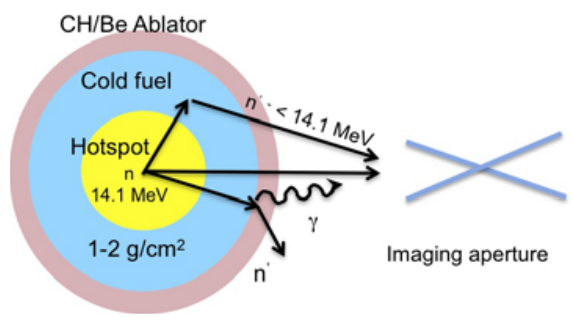

(a) Image formation processes

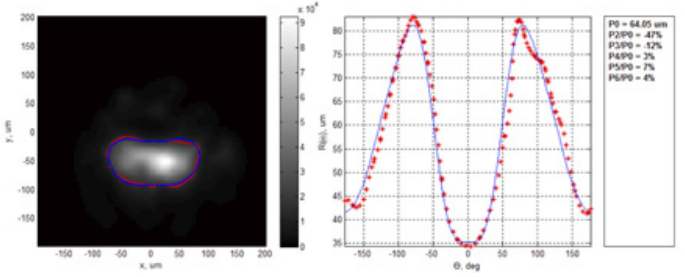

(b) First neutron image data

Figure 1. Description of the physical processes contributing to neutron imaging and the first reconstructed pinhole image data collected by the NIF system, shot N110217.

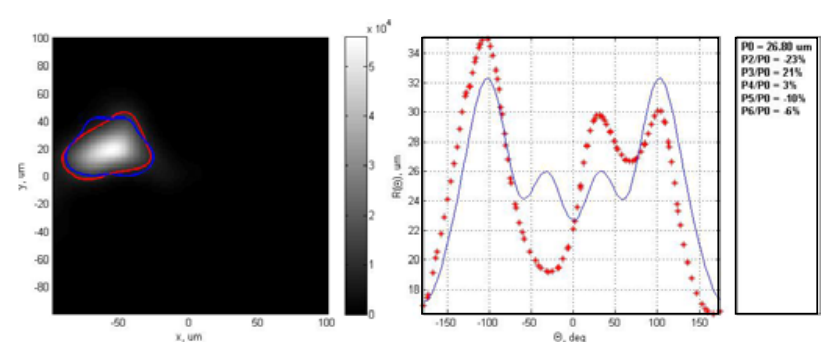

Figure 2. Reconstructed pinhole image from the first layered implosion data collected by the NIF neutron imaging diagnostic. The target was a cryogenically layered $\mathrm{CH}$ capsule filled with $15 \% \mathrm{H}, 20 \% \mathrm{D}$ and $65 \% \mathrm{~T}$ and driven by $1.3 \mathrm{MJ}$ of $351 \mathrm{~nm}$ energy.

beams to provide significant drive at the waist of the target due to the high glancing angle. In spite of this, the data show good agreement with X-ray imaging data, as well as post-shot simulations of the size and shape of the fuel assembly, as described by Wilson et al. [12].

\subsection{Images from cryogenically layered targets}

Since commissioning, the neutron imaging diagnostic has participated in eight cryogenically layered DT and HTD implosion experiments. A typical HTD filled plastic capsule is designed with a $57 \mu \mathrm{m}$ thick CH ablator and filled with a mixture of $\mathrm{H}$ (15 atm\%), D (20 atm\%), and $\mathrm{T}$ ( $65 \mathrm{~atm} \%)$, maintaining an average atomic mass number of 2.5. Capsules were driven with $1.3 \mathrm{MJ}$ of $351 \mathrm{~nm}$ radiation at a peak power near 420 TW. Fig. 2 shows the reconstructed primary neutron image from shot N110603, with the $17 \%$ of peak signal contour indicated by the red line and the corresponding fit using Legendre polynomials by the blue line. The resulting Legendre mode description of the low mode shape is: $\mathrm{P} 0=25 \pm 3 \mu \mathrm{m}$, and $\mathrm{P} 2 / \mathrm{P} 0=-24 \pm 3 \%$. The error bar quoted is a combined error bar including the systematic uncertainty in the fit. This was determined by the fit uncertainties and a replicate trials study using the current noise model of the image system. The neutron yield and downscattered ratio of this shot was $6.45 \mathrm{E}+13 \pm 1.53 \mathrm{E}+12$, and $4.4 \pm 0.3 \%$, therefore the number neutrons in the $10-12 \mathrm{MeV}$ band was below the sensitivity threshold $(\sim 2 \mathrm{E}+13)$ for pinhole imaging.

Figs 3 and 4 show the reconstructed primary and 10-12 MeV scattered images from shot N110608002-999, which produced a primary neutron yield of $1.9 \mathrm{E}+14 \pm 4.4 \mathrm{E}+13$ and a downscattered neutron flux ratio (DSR) between the $10-12 \mathrm{MeV}$ and $13-17 \mathrm{MeV}$ bands of $4.4 \pm 0.2 \%$. At these yields and DSR levels, a penumbral downscattered image reconstruction may be performed. The capsule used in this implosion was similar to shot N110603-001-999, but filled with equimolar DT. The resulting P0 and 


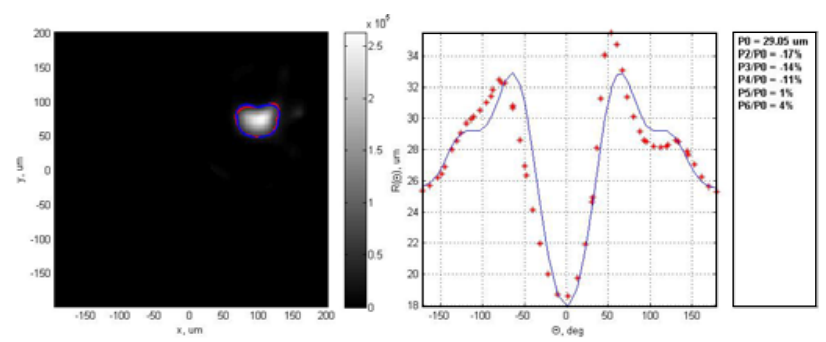

Figure 3. Reconstructed pinhole image data of primary neutrons from shot N110608-001-999. Shot N110608 was a cryogenically layered equimolar DT filled capsule shot at $1.3 \mathrm{MJ}$ of $351 \mathrm{~nm}$ energy. The result of the fit gives: $\mathrm{P} 0=29 \pm 4 \mu \mathrm{m}$, and $\mathrm{P} 2 / \mathrm{P} 0=-17 \pm 4 \%$.

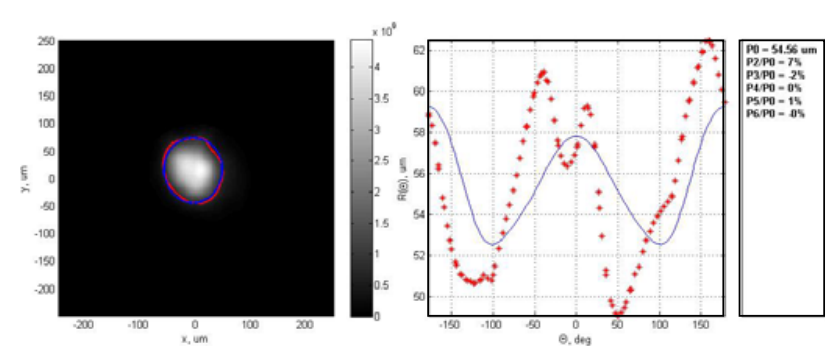

Figure 4. First reconstructed penumbral aperture image of scattered neutrons in the $10-12 \mathrm{MeV}$ band. This data was produced in shot N110608-002-999. The fit results are: $\mathrm{P} 0=54.6 \pm 6 \mu \mathrm{m}$ and $\mathrm{P} 2 / \mathrm{P} 0=7 \pm 3 \%$.

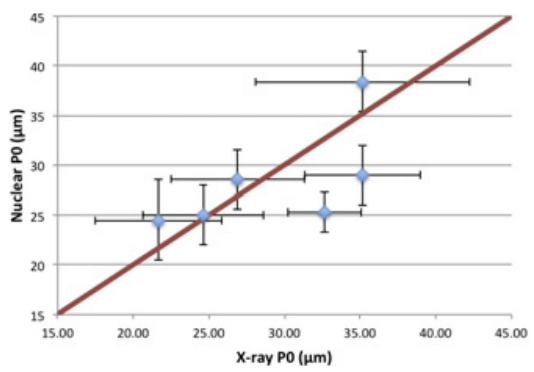

(a) Neutron vs. X-ray P0

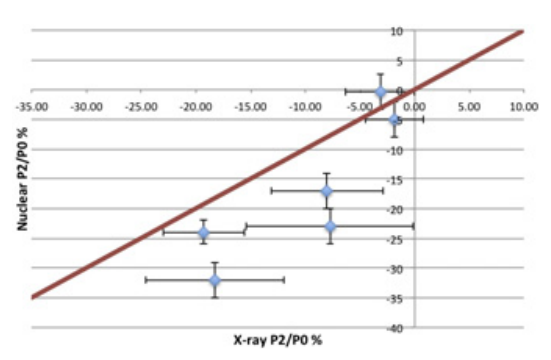

(b) Neutron vs. X-ray P2/P0

Figure 5. Comparison of the neutron and X-ray measurements of the size and shape of the hot-spot in cryogenically layered DT and THD implosions at the NIF.

$\mathrm{P} 2 / \mathrm{P} 0$ ratio for the primary and downscattered reconstructions are: $\mathrm{P} 0_{\text {prim }}=29 \pm 4 \mu \mathrm{m}, \mathrm{P} 2 / \mathrm{P} 0_{\text {prim }}=$ $-17 \pm 4 \%$, and $\mathrm{P}_{\text {sec }}=54 \pm 7 \mu \mathrm{m}, \mathrm{P} 2 / \mathrm{P}_{\text {sec }}=-7 \pm 3 \%$. The downscattered ratio expected from this geometry, and under the assumption of an isobaric configuration, concentric registration of the image centroids, and fuel mass conservation, is about $4 \%$, in good agreement between this image data and other measurements of the neutron fluence from the implosion.

\subsection{Comparison with $x$-ray image data}

Figs $5 \mathrm{a}$ and $5 \mathrm{~b}$ show a comparison of the primary neutron image and X-ray images collected at peak burn. The data were produced in the series of layered cryogenic implosions during the summer of 2011. The X-ray data were collected at a position rotated $123^{\circ}$ around the hohlraum axis from the neutron 
imager. The data show good agreement, indicating that the X-rays are produced in the same hot volume, and that the 9-11 keV energy $\mathrm{X}$-ray production is dominated by temperature and not density.

\section{SUMMARY}

During 2011, the NIF neutron imaging system was implemented and operationally qualified. The system has collected images of polar direct drive implosions of DT filled micro balloons, as well as indirectly driven layered cryogenic implosions of HTD and DT filled plastic capsules. These data have been analyzed for fuel assembly size and shape data, indicating that direct drive implosions are approximately two times larger than indirect drive implosions and substantially more asymmetric. The NIF neutron imager has also collected primary and scattered neutron images of cryogenically layered HTD and DT filled $\mathrm{CH}$ shells, with the scattered neutron images representing an experimental first. The size and shape of the neutron hot-spot shows quantitive agreement with the x-ray image data, indicating the $\mathrm{X}$-ray emission appears to be dominated by the hot core of the implosion.

This work was performed for the U.S. Department of Energy, National Nuclear Security Administration and by the National Ignition Campaign partners; Lawrence Livermore National Laboratory (LLNL), University of Rochester -Laboratory for Laser Energetics (LLE), General Atomics(GA), Los Alamos National Laboratory (LANL), Sandia National Laboratory (SNL). Other contributors include Lawrence Berkeley National Laboratory (LBNL), Massachusetts Institute of Technology (MIT), Atomic Weapons Establishment (AWE), England, and Commissariat à l'Énergie Atomique (CEA), France. LA-UR 11-06250

\section{References}

[1] D. Ress, R.A. Lerche, R.J. Ellis, S.M. Lane, K.A. Nugent, Rev. Sci. Instrum. 59, 1694 (1988)

[2] J.P. Garçonnet, O. Delage, D. Schirmann, A. Bertin, G. Grenier, B. Guilpar, A. Rouyer, Lasers Part. Beams 12, 563 (1994)

[3] L. Disdier, A. Rouyer, D. Wilson, A. Fedotoff, C. Stoeckl, J.L. Bourgade, V.Y. Glebov, J.P. Garçonnet, W. Seka, Nucl. Instrum. Meth. A 489, 496 (2002)

[4] C.R. Christensen, C. Barnes, G. Morgan, M. Wilke, D.C. Wilson, Rev. Sci. Instrum. 74, 2690 (2003)

[5] G.P. Grim, G.L. Morgan, M.D. Wilke, P.L. Gobby, C.R. Christensen, D.C. Wilson, Rev. Sci. Instrum. 75, 3572 (2004)

[6] G. Grim, C. Barnes, P. Bradley, C. Christensen, A. Hauer, G. Morgan, J. Oertel, M. Wilke, D. Wilson, C. Barrera et al., Jour. de Phys. IV 133, 913 (2006)

[7] C.H. Wilde, D.D. Clark, V.E. Fatherley, G.P. Grim, S.A. Jaramillo, A.J. Montoya, G.L. Morgan, J.A. Oertel, T.A. Ortiz, J.R. Payton et al. (2007)

[8] M.D. Wilke, S.H. Batha, P.A. Bradley, R.D. Day, D.D. Clark, V.E. Fatherley, J.P. Finch, R.A. Gallegos, F.P. Garcia, G.P. Grim et al., Rev. Sci. Instrum. 79, 10E529 (2008), http://link. aip.org/link/?RSI/79/10E529/1

[9] D.N. Fittinghoff, D.P. Atkinson, D.E. Bower, O.B. Drury, J.M. Dzenitis, B. Felker, M. Frank, S.N. Liddick, M.J. Moran, G.P. Roberson et al., these proceedings

[10] R.F. Wagner, D.G. Brown, C.E. Metz, Proceedings of the SPIE 314, 72 (1981)

[11] V.I. Gelfgat, E. Kosarev, E. Podolyak, Comp. Phys. Comm. 74, 335 (1993)

[12] D.C. Wilson, T.N. Arhculeta, R.J. Aragonez, D.P. Atkinson, M.A. Barrios, S.H. Batha, D.E. Bower, D.K. Bradley, R.A. Buckles, D.D. Clark et al., these proceedings 